\title{
MicroRNA-29c-5p suppresses gallbladder carcinoma progression by directly targeting CPEB4 and inhibiting the MAPK pathway
}

\author{
Yi-Jun Shu ${ }^{1,2,3}$, Run-Fa Bao ${ }^{1,2,3}$, Lin Jiang ${ }^{1,2,3}$, Zheng Wang ${ }^{1,2,3}$, Xu-An Wang ${ }^{1,2}$, Fei Zhang ${ }^{1,2}$, Han-Bin Liang ${ }^{1,2}$, Huai-Feng Li ${ }^{1,2}$, \\ Yuan-Yuan $\mathrm{Y}^{1,2}$, Shan-Shan Xiang ${ }^{1,2}$, Hao Weng ${ }^{1,2}$, Xiang-Song Wu ${ }^{1,2}$, Mao-Lan Li ${ }^{1,2}$, Yun-Ping Hu ${ }^{1,2}$, Wei Lu ${ }^{1,2}$, Yi-Jian Zhang ${ }^{1,2}$, \\ Jian Zhu ${ }^{*, 1,2}$, Ping Dong ${ }^{*, 1,2}$ and Ying-Bin Liu ${ }^{*, 1,2}$
}

Gallbladder cancer (GBC) is a leading cause of cancer-related deaths worldwide, and its prognosis remains poor, with a 5-year survival rate of $\sim 5 \%$. Given the crucial role of microRNAs (miRNAs) in cancer metastasis, we aimed to analyze the expression and function of the metastasis-associated miRNA miR-29c-5p in GBC. We validated that expression of miR-29c-5p was significantly downregulated in GBC and was closely associated with lymph node metastasis, overall survival and disease-free survival in $\mathbf{4 0}$ GBC patients who were followed clinically. Ectopic overexpression of miR-29c-5p dramatically repressed proliferation, metastasis, and colony formation and induced apoptosis in vitro, and it suppressed tumorigenicity in vivo through the MAPK pathway. Cytoplasmic polyadenylation element binding protein 4 (CPEB4) was identified as a critical effector target of miR-29c-5p. Enforced expression of miR-29c-5p significantly inhibited the expression of CPEB4, and restoration of CPEB4 expression reversed the inhibitory effects of miR-29c-5p on GBC cell proliferation and metastasis. Transforming growth factor- $\beta$ (TGF- $\beta$ ) upregulated CPEB4 by downregulating miR-29c-5p, leading to MAPK pathway activation. In conclusion, the TGF- $\beta / \mathrm{miR}-29 \mathrm{c}-5 \mathrm{p} / \mathrm{CPEB} 4$ axis has a pivotal role in the pathogenesis and poor prognosis of GBC, suggesting that miR-29c-5p is a tumor-suppressive miRNA that may serve as potential prognostic biomarker or therapeutic target for GBC.

Cell Death and Differentiation (2017) 24, 445-457; doi:10.1038/cdd.2016.146; published online 6 January 2017

Gallbladder cancer (GBC) is the most common biliary tract malignancy and the seventh most common gastrointestinal cancer. ${ }^{1}$ The Surveillance, Epidemiology, and End Results (SEER) Program estimates the incidence of GBC to be 2.5 cases per $1 \times 10^{5}$ people. Despite its relatively low incidence rate, GBC-associated mortality is higher than that of other cancers. ${ }^{2}$ The prognosis for advanced gallbladder carcinoma is very poor, and the 5-year survival rate is only $\sim 5 \%$. $^{3}$ This poor survival rate is due to the early lymphatic, perineural, and hematogenous spread of tumors and to direct tumor invasion into the liver. ${ }^{4}$ Therefore, patient prognoses may be improved by identifying novel and effective therapeutic targets for the treatment of this disease and by increasing our understanding of biomarkers that can predict therapeutic responses.

MicroRNAs (miRNAs) are endogenous, small, noncoding, regulatory RNAs that are $\sim 22 \mathrm{nt}$ long. ${ }^{5}$ As post-transcriptional regulators, miRNAs can negatively regulate gene expression by binding directly to the $3^{\prime}$ - untranslated regions (3'-UTRs) of corresponding target messenger RNAs (mRNAs) in a sequence-specific manner, thereby inducing mRNA degradation or the repression of protein translation. ${ }^{5}$ Since the first miRNA was reported by Ambros and Ruvkun in $1993,{ }^{6,7}$ many miRNAs have been demonstrated to actively participate in the regulation of tumor development as tumor-suppressor genes or oncogenes. ${ }^{8,9}$ Although the importance of miRNAs in metastasis has attracted much attention in recent years, the pathological relevance and significance of the majority of miRNAs to $\mathrm{GBC}$ remain unclear. $^{10}$

In this study, we first compared the miRNA expression profiles of GBC tissues and their matched non-tumorcounterparts by miRNA array analysis. On the basis of its association with GBC metastasis, miR-29c-5p was chosen for further study. The biological functions and molecular mechanisms of miR-29-5p in the progression of GBC were comprehensively investigated in vitro and in vivo.

\section{Results}

Identification of miRNAs that were differentially expressed in GBC and NATs. A miRNA microarray analysis was performed to compare the miRNA expression profiles of GBC tissues and NATs. The results showed significant alterations ('>2-fold) in the levels of 13 miRNAs, including 11 miRNAs that were downregulated and two miRNAs that were upregulated (Figure 1a). Among these, miR-29c was most dramatically downregulated in GBC tissues compared with NATs, consistent with other studies

\footnotetext{
${ }^{1}$ Department of General Surgery and Laboratory of General Surgery, Xinhua Hospital, Affiliated with Shanghai Jiao Tong University School of Medicine, No. 1665 Kongjiang Road, Shanghai 200092, China and ${ }^{2}$ Institute of Biliary Tract Disease, Shanghai Jiao Tong University School of Medicine, No. 1665 Kongjiang Road, Shanghai 200092 , China

${ }^{*}$ Corresponding author: J Zhu or P Dong or Y-B Liu, Department of General Surgery, Xinhua Hospital,Affiliated to Shanghai Jiao Tong University School of Medicine, No. 1665 Kongjiang Road, Shanghai 200092, China. Tel/Fax: +86-21-25076880; E-mail: 69ZJ@sina.com or dongping1050@163.com or liuybphd@126.com

${ }^{3}$ These authors contributed equally to this work.

Received 02.2.16; revised 02.10.16; accepted 08.11.16; Edited by L Zitvogel; published online 06.1.2017
} 
a

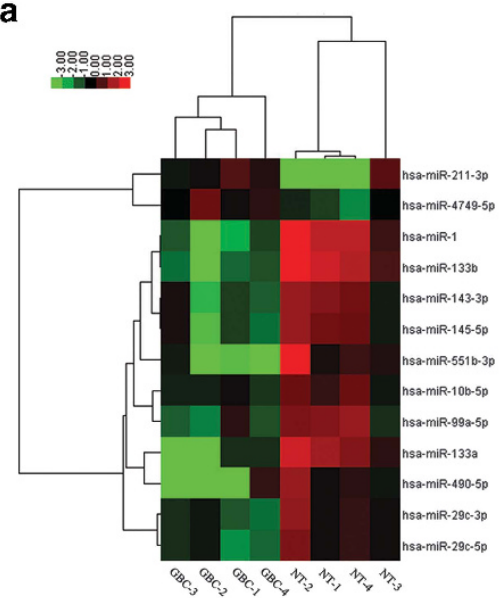

C

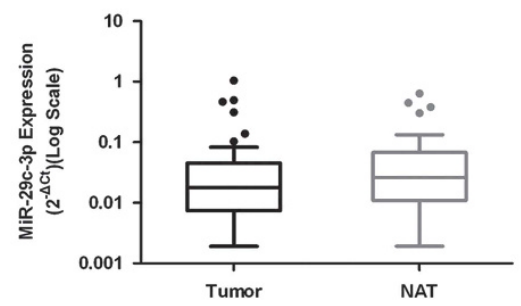

b
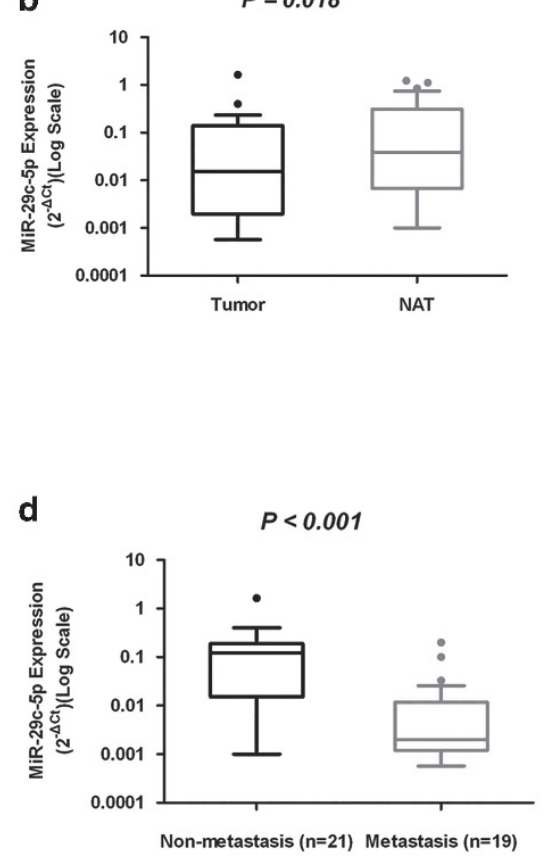

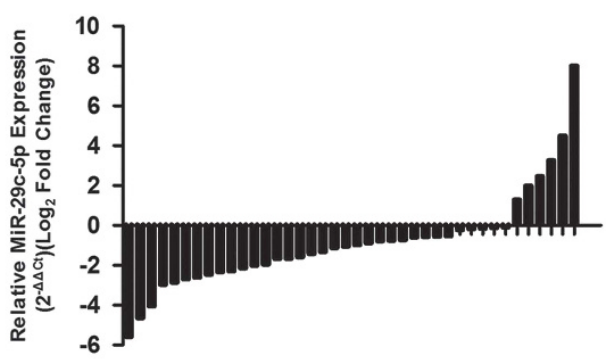

e

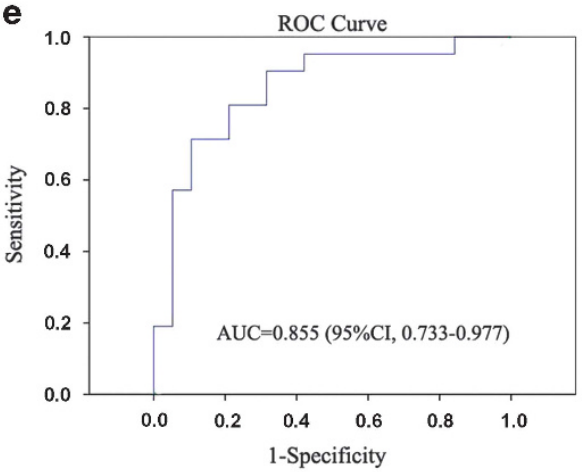

f

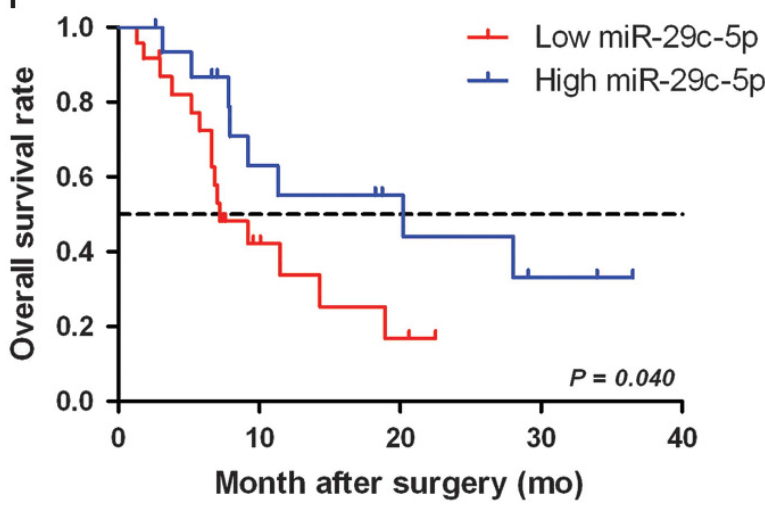

g

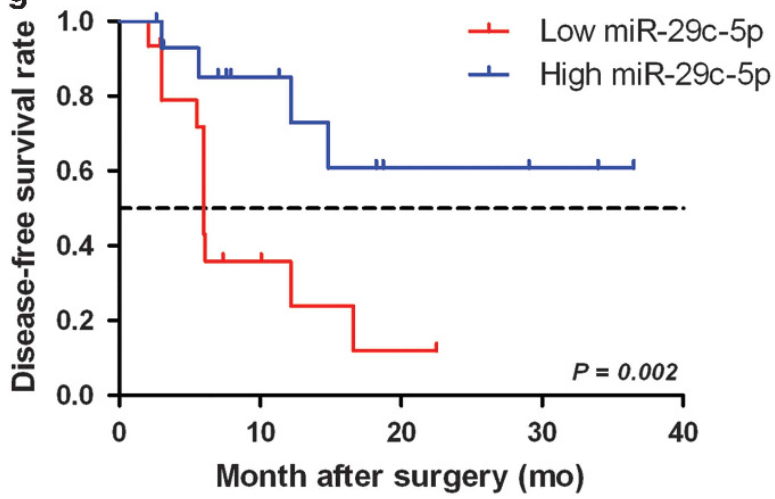

Figure 1 miR-29c-5p is frequently downregulated in GBC and is a promising prognostic biomarker for GBC. (a) A portion of the cluster analysis of the miRNA expression profiles of GBC tissues and NATs. (b) Expression of miR-29c-5p in 40 pairs of GBC tissues and their corresponding NATs. The expression levels of miR-29c-5p were determined by qRT-PCR and normalized to an endogenous control (U6 RNA). The data were analyzed using the formula $2^{-\triangle C T}$. (c) Expression of miR-29c-3p in 40 pairs of GBC tissues and their corresponding NATs. (d) Box plot of miR-29c-5p expression with or without metastasis. (e) Receiver operating characteristic (ROC) curve analysis to predict lymph node metastasis. ( $\mathbf{f}$ and $\mathbf{g}$ ) The OS and DFS of patients with high or low miR-29c-5p expression

indicating that $\mathrm{miR}-29 \mathrm{c}$ is a key mediator of tumorigenesis. ${ }^{11,12,13}$ We measured the expression levels of miR-29c-3p and $-5 p$ in 40 pairs of GBC tissues and their corresponding NATs by qRT-PCR. Consistent with the miRNA array data, miR-29c-5p expression was significantly downregulated in the tumor tissues compared with the NATs $(P=0.018$; Figure 1b). However, miR-29c-3p did not show a significant decrease in expression $(P=0.774$; Figure 1c). We thus focused on miR-29c-5p in our subsequent investigation. When compared with non-metastatic GBC patients, GBC patients who developed metastasis harbored the lowest expression levels of miR-29c-5p $(P<0.001$; Figure 1d), potentially implicating the involvement of miR-29c-5p in the metastasis of GBC.

Correlations between miR-29c-5p expression and the clinicopathologic characteristics and prognosis of GBC. Because miR-29c-5p expression levels correlated with lymph node metastasis, we further investigated the diagnostic potential of miR-29c-5p expression for predicting GBC 
metastasis. We found that the area under the receiver operating characteristic (ROC) curve (AUC) of the miR-29c$5 p$ expression levels was 0.855 (95\% Cl: 0.733-0.977; Figure 1e). The optimal cut-off value for the miR-29c-5p expression level $\left(2^{-\triangle \mathrm{CT}}=0.032\right)$ was selected based on an ROC curve analysis; thus, the miR-29c-5p expression levels in the GBC tissues were classified into either a lowexpression group or a high-expression group. Using these criteria, the correlations between miR-29c-5p expression levels, and both the clinicopathologic characteristics and the prognosis of GBC were analyzed. The miR-29c-5p expression levels were significantly lower in GBC tissues with lymph node metastasis $(P<0.001$; Table 1$)$.

More intriguingly, the survival analysis showed that GBC patients with high miR-29c-5p expression were characterized by better overall survival (OS) and disease-free survival (DFS) than patients with low miR-29c-5p expression (1- and 3-year OS: 55.7 and $33.4 \%$ versus 32.0 and $16.0 \%, P=0.040 ; 1$ - and 3-year DFS: 85.1 and $60.8 \%$ versus 35.9 and $12.0 \%$, $P=0.002$; Figures $1 \mathrm{f}$ and $\mathrm{g}$ ).

Univariate and multivariate survival analyses of the OS and DFS were also performed(Supplementary Table S2 and S3). Patients with high miR-29c-5p expression were associated with a better prognosis.

miR-29c-5p has a key role in GBC cell proliferation in vitro and in vivo. To explore the biological functions of miR-29c in GBC development, the expression levels of miR-29c-3p and $-5 p$ in five GBC cell lines and a normal biliary epithelia cell line were measured (Figure 2a). Consistent with the tumor tissue profiles, the GBC cells expressed lower levels of miR-29c-5p than miR-29c-3p.

To functionally characterize miR-29c-5p in GBC, we introduced the miR-29c precursor (pre-miR-29c) and its specific inhibitor anti-miR-29c-5p into the GBC-SD and NOZ cell lines. The different expression levels of miR-29c-5p were confirmed by real-time PCR (Figure $2 \mathrm{~b}$ and Supplementary Figure S1D).

CCK8 and colony-formation assays were performed to assess the role of miR-29c-5p in GBC cell proliferation. The results showed that, the proliferation of the pre-miR-29c cells was significantly reduced compared with the pre-miR-NC cells, while the proliferation of the anti-miR-29c-5p cells was significantly increased compared with the anti-NC cells (Figures 2c and d), consistent with an inhibitory role for this miRNA in GBC cell proliferation. Cell-cycle distribution analysis showed that the overexpression of miR-29c-5p led to a significant G1-phase arrest of the GBC cells, suggesting that the G1/S cell-cycle transition is blocked by miR-29c-5p. Cell cycle progression is controlled by periodic activation of several Cdk/cyclin complexes. Cyclin D1 is a key player in G1 phase progression. As a result, we suggested that miR-29c-5p induced $\mathrm{G} 1$ phase arrest by downregulating cyclin $\mathrm{D}$ to block the restriction point. Chk1 and Chk2 are effector kinases activated by phosphorylated ATR/ATM. ${ }^{14}$ Chk1 and Chk2 have been reported to phosphorylate $\mathrm{Rb}$ at Ser780 after DNA damage, leading to the formation of $\mathrm{pRb}-\mathrm{E} 2 \mathrm{~F}-1$ and cell cycle arrest. $^{15}$ We found that the expression of p-Chk1 (S-345) and p-Chk2 (T68), the activated Chk1 and Chk2, were increased after overexpressing miR-29c-5p (Figure $2 e$ and
Table 1 Association of miR-29c-5p expression with GBC clinicopathological characteristics

\begin{tabular}{|c|c|c|c|c|c|}
\hline \multirow[t]{2}{*}{ Variable } & \multirow[t]{2}{*}{ Category } & \multicolumn{2}{|c|}{$\begin{array}{l}\text { Relative miR-29c- } \\
5 p \text { expression }\end{array}$} & \multirow[t]{2}{*}{$x^{2}$} & \multirow[t]{2}{*}{$P$} \\
\hline & & $\begin{array}{c}\text { Low } \\
(n=23)\end{array}$ & $\begin{array}{l}\text { High } \\
(n=17)\end{array}$ & & \\
\hline Age & $\begin{array}{l}<60 \\
\geqslant 60\end{array}$ & $\begin{array}{c}6 \\
17\end{array}$ & $\begin{array}{c}6 \\
11\end{array}$ & 0.395 & 0.728 \\
\hline Sex & $\begin{array}{c}\text { Male } \\
\text { Female }\end{array}$ & $\begin{array}{l}10 \\
13\end{array}$ & $\begin{array}{c}4 \\
13\end{array}$ & 1.710 & 0.315 \\
\hline Tumor size $(\mathrm{cm})$ & $\begin{array}{l}<3 \\
\geqslant 3\end{array}$ & $\begin{array}{c}6 \\
11\end{array}$ & $\begin{array}{l}7 \\
3\end{array}$ & 3.038 & 0.120 \\
\hline $\begin{array}{l}\text { Histology } \\
\text { differentiation }\end{array}$ & $\begin{array}{c}\text { Well or } \\
\text { moderate } \\
\text { Poor }\end{array}$ & $\begin{array}{l}16 \\
7\end{array}$ & $\begin{array}{c}13 \\
4\end{array}$ & 0.234 & 0.629 \\
\hline $\begin{array}{l}\text { Tumor invasion } \\
\text { (AJCC) }\end{array}$ & $\begin{array}{l}\text { Tis- } T_{2} \\
\mathrm{~T}_{3}-\mathrm{T}_{4}\end{array}$ & $\begin{array}{c}5 \\
18\end{array}$ & $\begin{array}{l}9 \\
8\end{array}$ & 4.183 & 0.052 \\
\hline $\begin{array}{l}\text { Lymph node } \\
\text { metastasis }\end{array}$ & $\begin{array}{l}\text { Yes } \\
\text { No }\end{array}$ & $\begin{array}{c}17 \\
6\end{array}$ & $\begin{array}{c}2 \\
15\end{array}$ & 15.140 & $<0.001$ \\
\hline $\begin{array}{l}\text { TNM stage } \\
\text { (AJCC) }\end{array}$ & $\begin{array}{l}\text { I-II } \\
\text { III-IV }\end{array}$ & $\begin{array}{c}5 \\
18\end{array}$ & $\begin{array}{c}6 \\
11\end{array}$ & 0.901 & 0.477 \\
\hline
\end{tabular}

Bolded values indicate statistical significance, $P<0.05$.

Supplementary Figure S2B). We speculated that miR-29c-5p promoted spontaneous DNA damage repairing to impede tumor progression by activating Chk1/2 and subsequently causing the G1 phase arrest.

An EdU retention assay was performed to examine the regulatory effect of miR-29c-5p on DNA replication. Following transfection with pre-miR-29c, the percentage of EdU-positive GBC cells was reduced compared with that following the control treatment (Figure $2 \mathrm{~g}$ and Supplementary Figure S1B).

To validate the observations obtained from the in vitro studies, we then compared the growth activity of NOZ cells in vivo. Consistent with the in vitro results, tumor growth was significantly inhibited in the presence of the miR-29c-5p agomir (Figure 2f). Moreover, IHC showed increased membrane localization of E-cadherin, lower expression of vimentin, a reduction in the number of Ki-67-positive cells, and the absence of phosphorylated MEK in the miR-29c-5p agomir-inoculated tumor tissues (Figure 2h).

miR-29c-5p inhibits GBC cell metastasis and invasion in vitro and in vivo by reducing epithelial-mesenchymal transition (EMT). A wound-healing assay revealed that increased expression of miR-29c-5p in GBC cells was associated with significantly slower wound closure, whereas reduced miR-29c-5p expression in GBC cells resulted in significantly faster wound closure $(P<0.05$; Figure $3 \mathrm{~b}$ and Supplementary Figure S1A). A Transwell assay with Matrigel demonstrated that the pre-miR-29c cells were less invasive than the pre-miR-NC cells, while the anti-miR-29c-5p cells were more invasive than the anti-NC cells $(P<0.001$; Figure $3 \mathrm{a}$ and Supplementary Figure S1C). Accordingly, western blot and immunofluorescence (ICC) analyses showed that expression of miR-29c-5p significantly increased the expression of the EMT-related genes E-cadherin and $\beta$-catenin, and decreased the expression of vimentin (Figures $3 c$ and $d$ and Supplementary Figure S1E-F). 

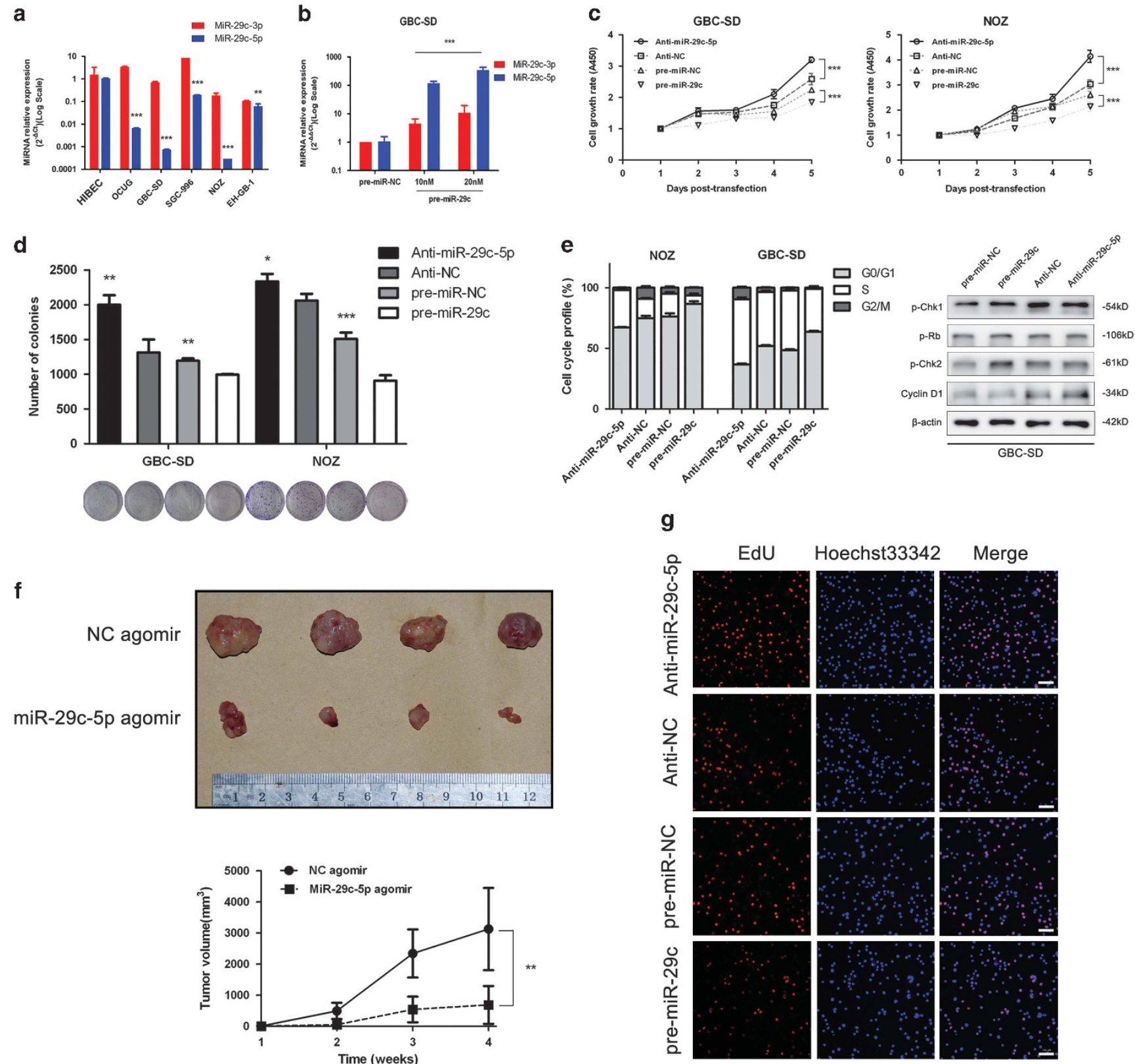

h

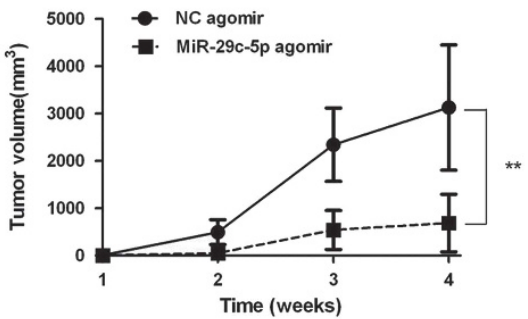

H\&E

Ki-67

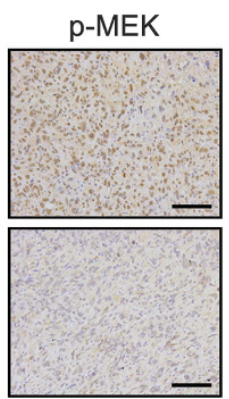

MEK
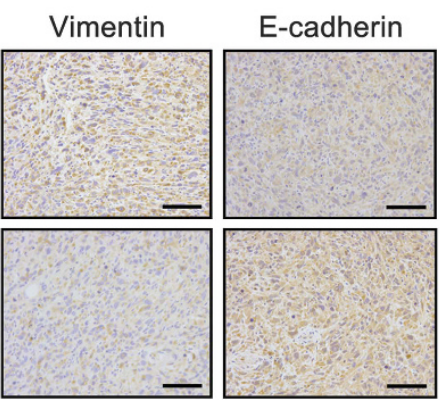

To confirm these findings in vivo, we employed a lung tumor metastasis assay via tail intravenous injection to monitor the metastatic ability of $\mathrm{NOZ}$ cells in nude mice. As shown in Figure $3 e$, the lung metastasis rate and the number of metastatic nodules per lung in the control group were significantly higher than those of the miR-29c-5p agomir-treated mice. These results indicated that miR-29c-5p inhibits GBC cell meta- 
Figure 2 miR-29c-5p represses GBC cell proliferation, colony formation and cell-cycle progression in vitro and in vivo. (a) The expression of miR-29c-3p and -5p in five GBC cell lines (GBC-SD, SGC-996, NOZ, OCUG, and EH-GB-1) and a normal biliary epithelia cell line (HIBEC)was analyzed by qRT-PCR. (b) GBC-SD cells were transiently transfected with pre-miR-29c (10 nM or $20 \mathrm{nM}$ ) or pre-miR-NC for $48 \mathrm{~h}$. The expression of miR-29c-3p and -5p was then analyzed.Growth curves (c), colony formation (d), and DNA replication ( $\mathbf{g}$ ) were assayed for GBC-SD cells and for NOZ cells infected with pre-miR-29c or negative control and with anti-miR-29c-5p or anti-NC. The number of colonies or the number of cells was counted and compared in the diagrams $\left({ }^{*} P<0.05,{ }^{* *} P<0.01\right.$, and $\left.{ }^{* * *} P<0.001\right)$. (e) Arrest at the G1/S cell-cycle transition induced by miR-29c-5p transfection. Protein expression levels of phospho-Chk1 (S345), phospho-Chk2 (T68), phospho-Rb (S780) and Cyclin D in the indicated cells were examined by western blotting. (f) Mice bearing NOZ subcutaneous xenografts were euthanized after 2 weeks of treatment with the miR-29c-5p agomir. The sizes of the tumors in the subcutaneous xenograft model were calculated and compared. (h) The expression of Ki-67, p-MEK, MEK, vimentin, and E-cadherin in local tumor tissues was determined by IHC staining

a

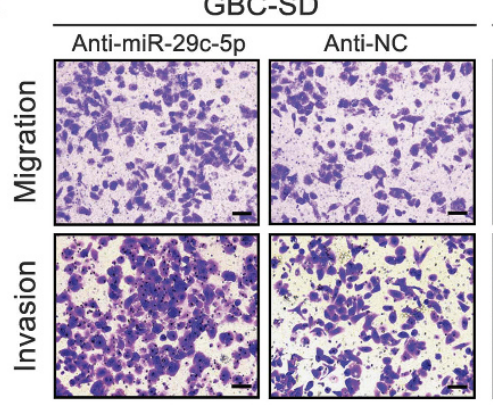

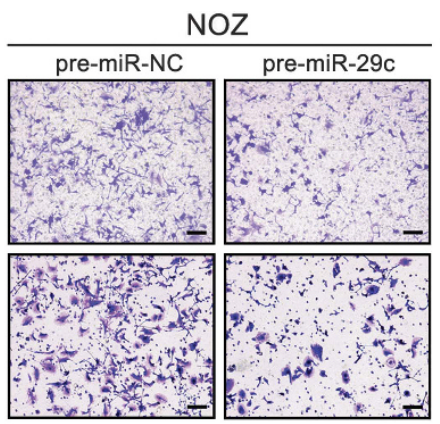

d

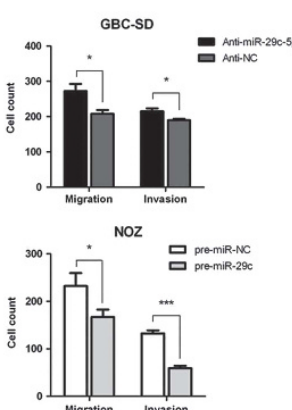

GBC-SD

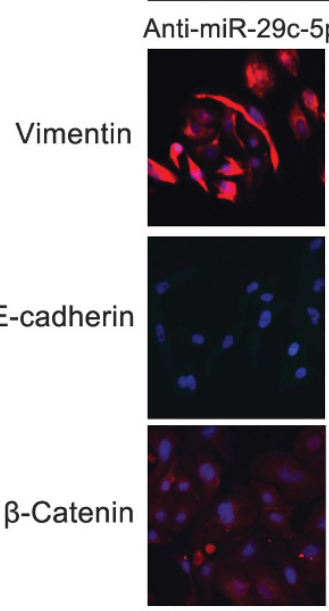

$5 \mathrm{p}$ Anti-NC
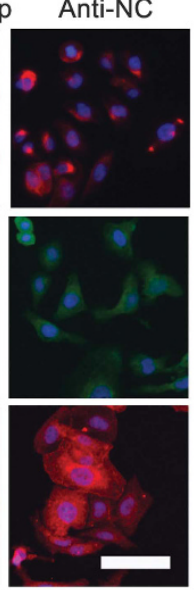

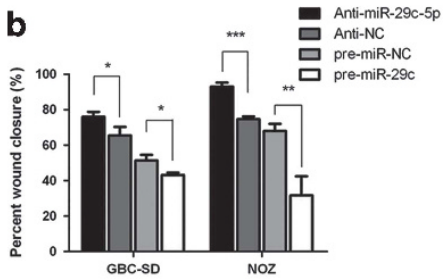

$\mathrm{NOZ}$

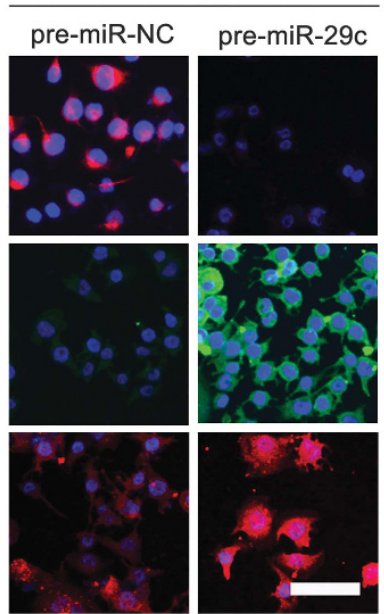

e

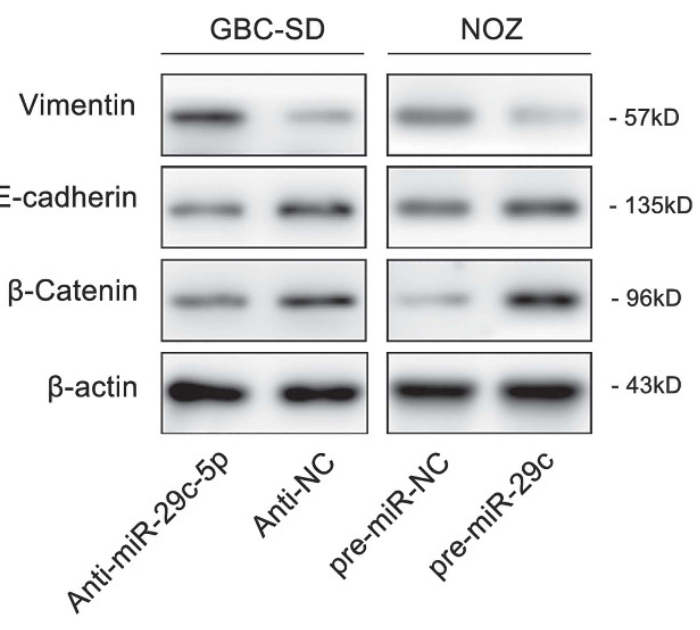

MiR-29c-5p agomir
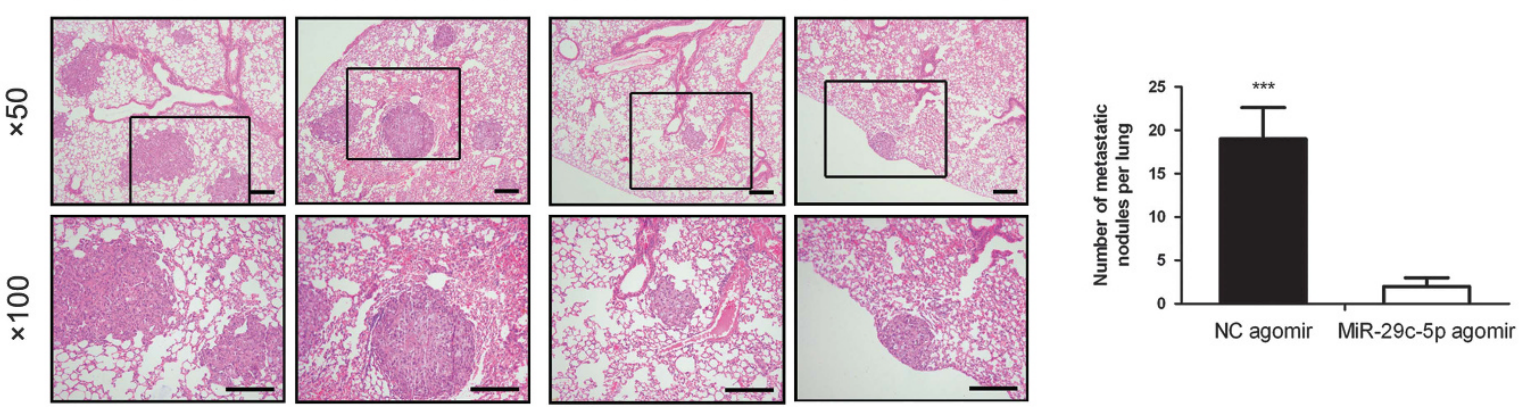

Figure 3 miR-29c-5p inhibits GBC cell migration and invasion in vitro and in vivo. (a) Transwell assays, with or without Matrigel, of GBC cells with miR-29c-5p overexpression or inhibition. The percentage of wound closure was calculated $(\mathbf{b})$, or the number of cells that passed through the membrane was counted and compared in the diagrams $\left({ }^{\star} P<0.05,{ }^{* \star} P<0.01\right.$, and $\left.{ }^{* \star *} P<0.001\right)$. (c and d) Protein expression levels of vimentin, E-cadherin, and $\beta$-catenin in the indicated cells were examined by western blotting and immunofluorescence analyses. Nuclei were counter stained with DAPI. (e) Representative images of lung metastases. The number of metastatic nodules in the lung was calculated and compared in the diagrams $\left({ }^{* \star *} P<0.001\right)$.Scale bar, $100 \mu \mathrm{m}$ 
a

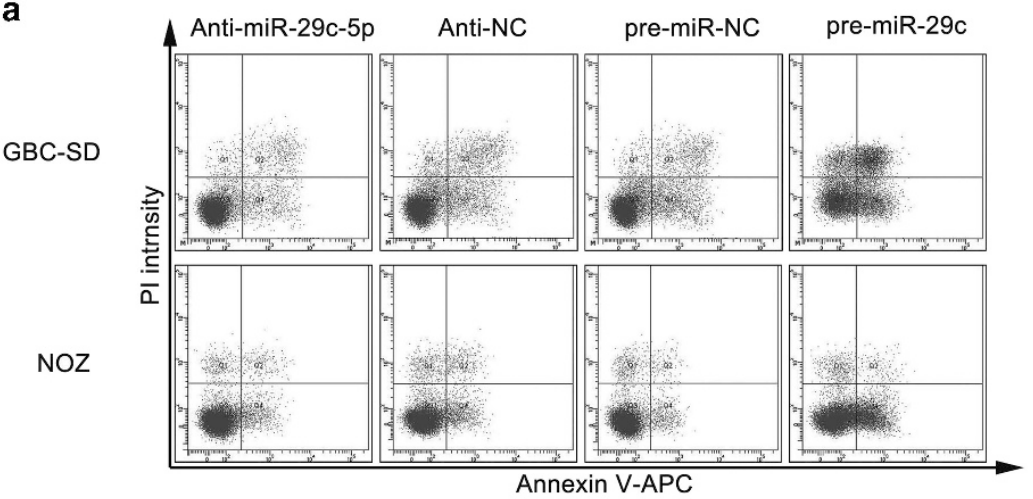

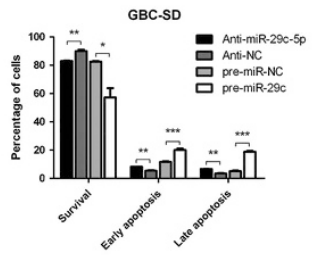

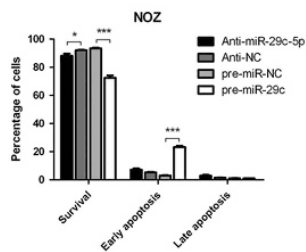

b

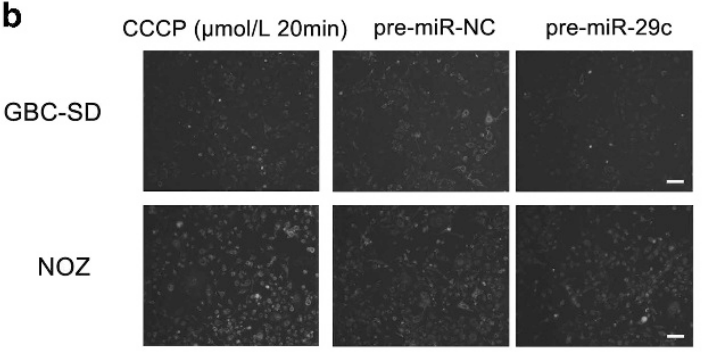

C

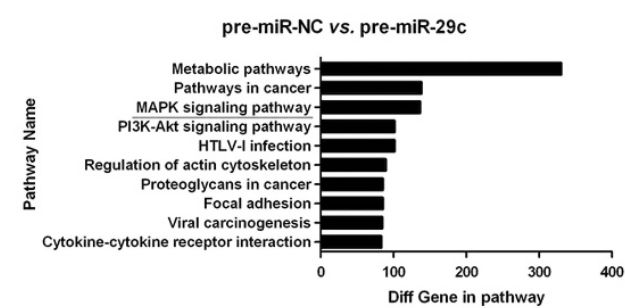

d

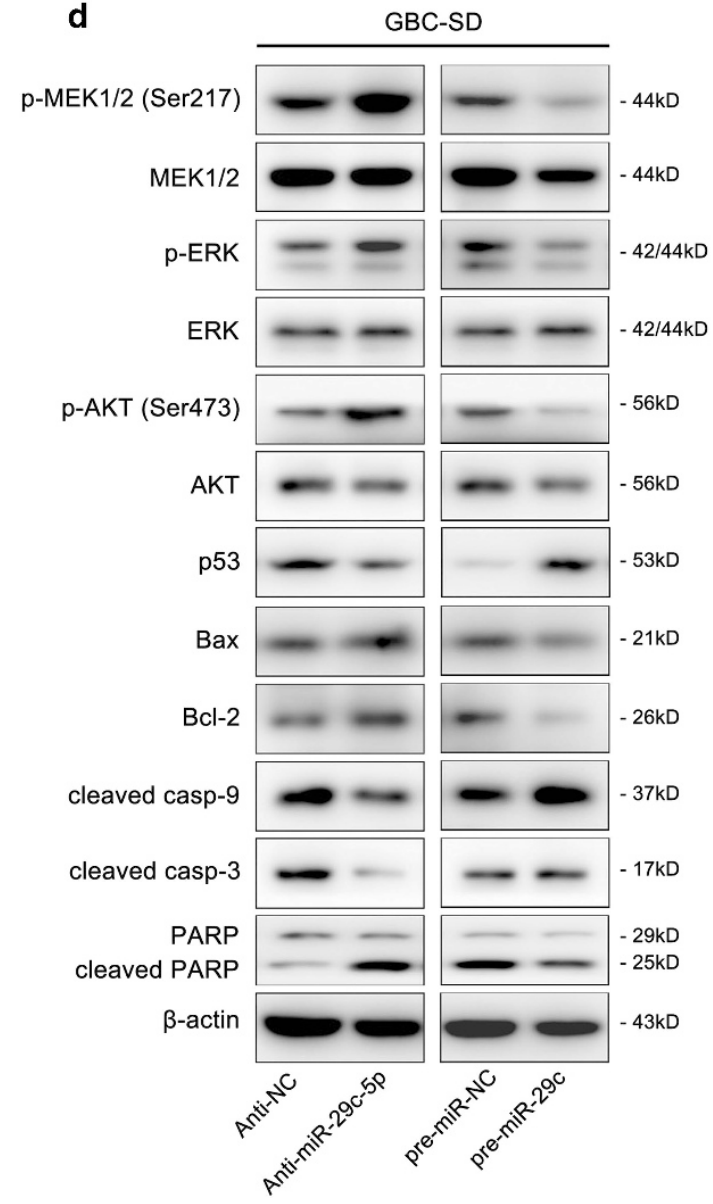

e
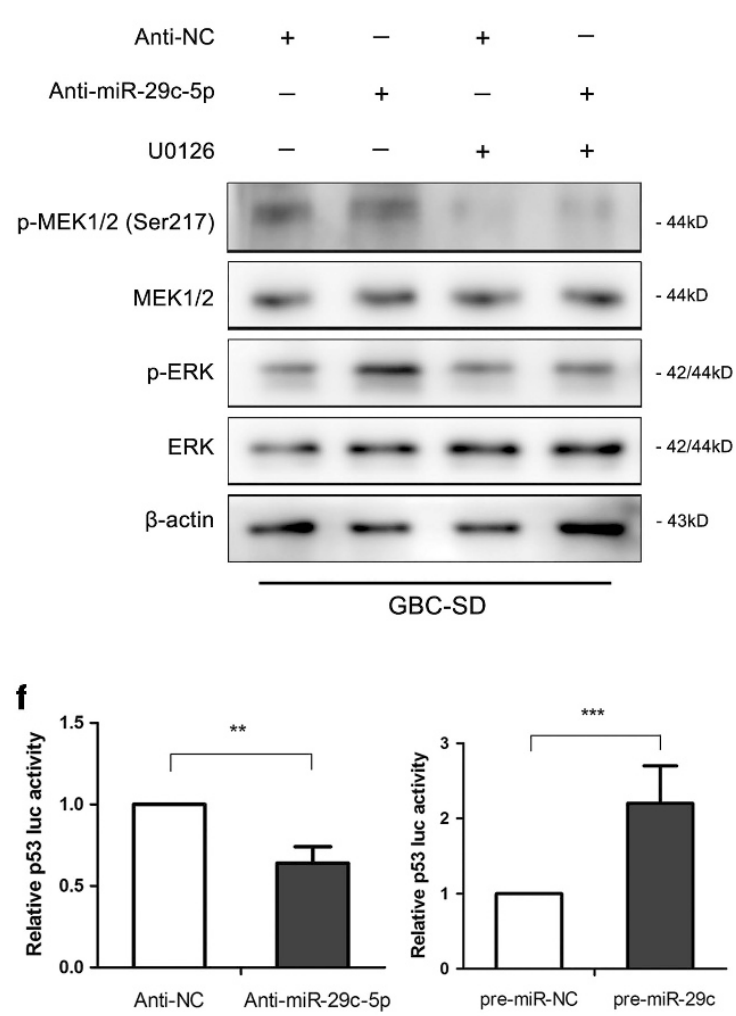
Figure 4 miR-29c-5p exerts an antiapoptotic effect via the MAPK pathway. (a) Apoptosis was analyzed by flow cytometry. Cells stained with Annexin-V-APC were considered to be apoptotic. The apoptotic index was defined as the percentage of apoptotic cells. (b) Analysis of the mitochondrial membrane potential ( $\Delta \Psi \mathrm{Im})$. The indicated cells were stained with JC-1, and green fluorescence represents de-energized mitochondria. The images were taken with a fluorescence microscope. CCCP was used as a positive control. (c) Identification of potential pathways downstream of miR-29c-5p with the Agilent Whole Human Genome Microarray (4×44 K), as described in the Materials and Methods. (d) Phosphorylation of MAPK/ERK pathway-associated proteins was detected in the indicated cells by western blot analysis. $\beta$-actin was used as the loading control. (e) MEK phosphorylation is significantly inhibited in cells treated with $20 \mu \mathrm{M}$ U0126 (MEK1/2 inhibitor). (f) 293T cells were co-transfected with pre-miR-29c (anti-miR-29c-5p) together with the pGL3-TP53/promoter and pRL-TK(pSV40-RL) plasmid. After $48 \mathrm{~h}$, luciferase activity was measured. Three independent experiments were carried out, and the relative luciferase activity is indicated $\left({ }^{\star \star} P<0.01\right.$, and $\left.{ }^{\star \star *} P<0.001\right)$.

stasis and invasion in vitro and in vivo via a reduction in EMT.

miR-29c-5p exerts an apoptotic effect through the MAPKJ ERK pathway. To explore the molecular mechanism by which miR-29c-5p inhibited the proliferation and metastasis of GBC cells, we investigated the effect of miR-29c-5p on apoptosis. The apoptotic indexes of the miR-29c-5p cells and the control cells were 38.76 and $25 \%$, respectively (for GBCSD cells, $P<0.001$ ), and 24.3 and $4 \%$, respectively (for NOZ cells, $P<0.001$; Figure 4a). Furthermore, the apoptotic index of the anti-miR-29c-5p cells was lower than that of the negative-control cells (Figure 4a). The $\mathrm{JC}-1$ probe is a fluorescent cationic dye that selectively accumulates in mitochondria via an electrochemical gradient and changes color from red to green as the mitochondrial membrane potential $(\Delta \Psi \mathrm{m})$ decreases. As illustrated in Figure $4 \mathrm{~b}$, the cells treated with pre-miR-29c demonstrated an increase in green fluorescence, indicating the loss of mitochondrial function. These results suggested that miR-29c-5p induces apoptosis through a mitochondria-dependent mechanism.

The gene expression profiles of GBC cells with or without miR-29c overexpression were determined using the Agilent Whole Human Genome Microarray $(4 \times 44 \mathrm{~K})$ to search for a potential pathway. By focusing on the most differentially expressed genes associated with miR-29c-5p, we speculated that the MAPK/ERK signaling pathway was the main pathway through which miR-29c-5p suppresses the tumorigenesis and metastasis of GBC (Figure 4c). Deregulation of MEK/ERK phosphorylation represents an important antiapoptotic mechanism in various cancers. ${ }^{16}$ The prime inducers of apoptotic pathways are proapoptotic and antiapoptotic Bcl-2 family proteins and caspases. During apoptosis, the permeability of the mitochondrial membrane increased, leading to a loss of membrane potential and release of cytochrome $c$ into the cytosol, which binds to apoptotic protease activating factor-1 (Apaf-1). ${ }^{17}$ The Bcl-2 and Bcl-xL proteins have been identified as antiapoptotic proteins, which bind to the outer membrane of the mitochondrion and prevent the release of cytochrome $c .^{18}$ The proapoptotic members of this family, Bax and Bak, are responsible for permeabilizing the membrane under stress and promoting the release of cytochrome $c$ from the mitochondria. ${ }^{19,20}$ Therefore, we conducted a western blot analysis of the phosphorylation status of proteins involved in the MAPK signaling pathway. Compared with control cells, miR-29c-5p overexpressing cells harbored decreased levels of phosphorylated MEK1/2, p44/42 MAPK (ERK1/2) and Akt at Ser473, while the total protein levels were unaffected by miR-29c-5p expression. Inactivated Akt subsequently regulates $\mathrm{Bcl}-2$ family proteins. As a result, the subsequent cleavages of caspase-9, caspase-3, and PARP were all increased in miR-29c-5p-overexpressing cells relative to control cells. The phosphorylation of MEK1/2, ERK and Akt was reversed when miR-29c-5p was inhibited in GBC cells (Figure 4d and Supplementary Figure S2A). Additionally, when we used MEK1/2 inhibitor (20 $\mu \mathrm{M}$ U0126) that sufficiently block MEK1/2 and ERK phosphorylation, the effect of miR-29c-5p disappeared almost completely (Figure $4 e$ and Supplementary Figure S2C). These results indicated that the MAPK/ERK pathway may participate in the miR-29c-5pinduced apoptosis of GBC cells.

It is reported that miR-29 family members upregulate p53 levels and induce apoptosis in a p53-dependent manner, ${ }^{21}$ but the role of $\mathrm{miR}-29 \mathrm{c}-5 \mathrm{p}$ in regulating $\mathrm{p} 53$ remains unexplored. The result showed that overexpression of miR-29c-5p could increase p53 protein levels, indicating that miR-29c-5p may activate p53 (Figure 4d). We, therefore, further conducted luciferase assays to determine whether TP53 promoter activity was regulated by miR-29c-5p expression. As expected, TP53 promoter activity was significantly increased after transfection of miR-29c-5p in 293T cells $(P<0.001$; Figure 4f). In addition, the transfection of antimiR-29c-5p decreased promoter activity by $40 \%$ compared with that of luciferase control (Figure 4f). These results indicate that miR-29c-5p induces the transcription of the TP53 gene.

CPEB4 is a direct target of miR-29c-5p. To address the molecular mechanisms by which miR-29c-5p regulates proliferation and metastasis in GBC, we employed a threestep approach to identify potential target genes of miR-29c$5 p$. First, we used computational prediction programs to identify genes whose $3^{\prime}$ UTR sequences were predicted to contain miR-29c-5p binding sites (Figure 5a). Second, a multi-pathway array was performed (Figure 4c). The results showed that miR-29c-5p expression selectively attenuated the activity of the MAPK/ERK pathway. We thus focused on this pathway to search for potential targets of miR-29c-5p. Third, conserved genes whose expression levels were reduced in response to $\mathrm{miR}-29 \mathrm{c}-5 \mathrm{p}$ treatment were selected as potential target genes for further experiments.

On basis of the above steps, CPEB4, which was associated with the MAPK/ERK pathway, 22 was selected for further experiments.We then conducted a luciferase-based assay to confirm whether CPEB4 was indeed regulated by miR-29c-5p. Pre-miR-29c, but not pre-miR-NC, specifically decreased the expression of the CPEB4-3'-UTR-WT luciferase reporter. In contrast, no change in the relative luciferase expression was observed in cells transfected with a CPEB4-3'-UTR-Mut reporter (Figure 5b). Western blot 
analysis and qPCR confirmed that miR-29c-5p suppressed the endogenous protein and mRNA levels of CPEB4 in $\mathrm{GBC}$ cells (Figure $5 \mathrm{c}$ and Supplementary Figure S3A).
Collectively, these results indicated that CPEB4 is a direct target of miR-29c-5p and can be negatively regulated by miR-29c-5p. a

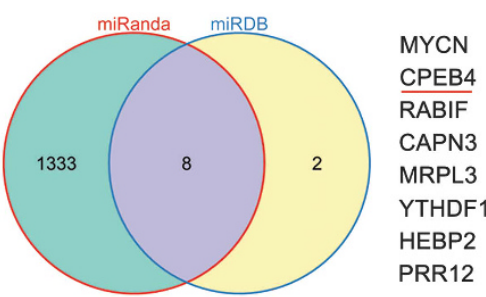

d

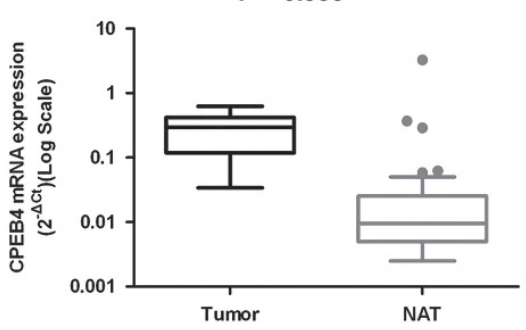

g
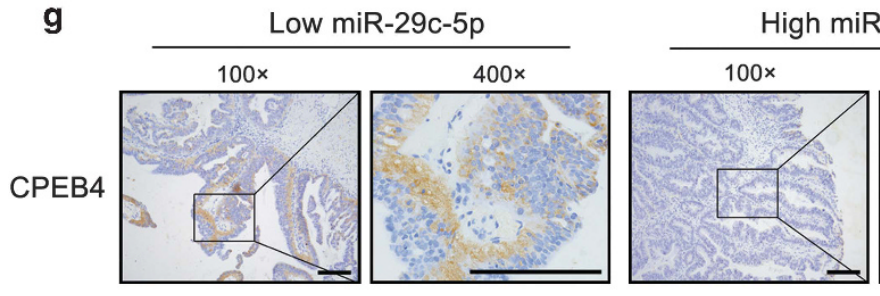

e

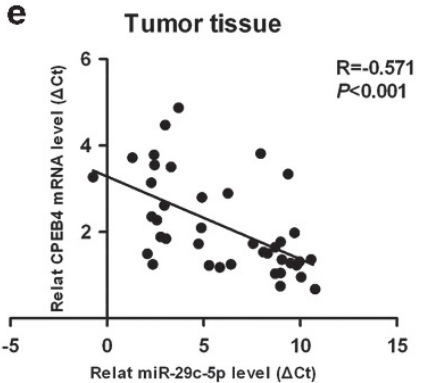

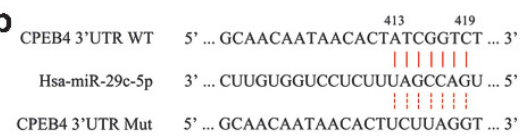

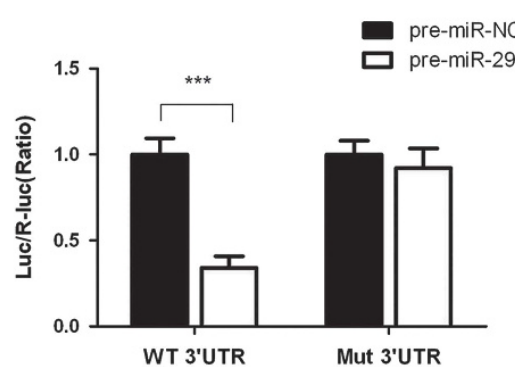

WT 3'UTR

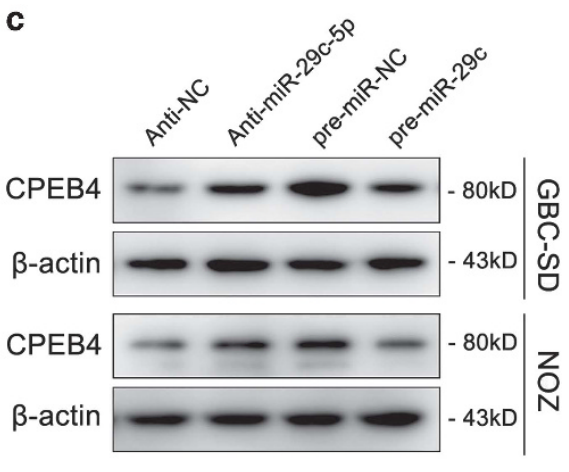

$\mathbf{f}$

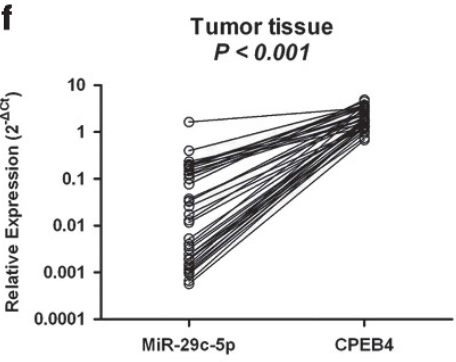

h

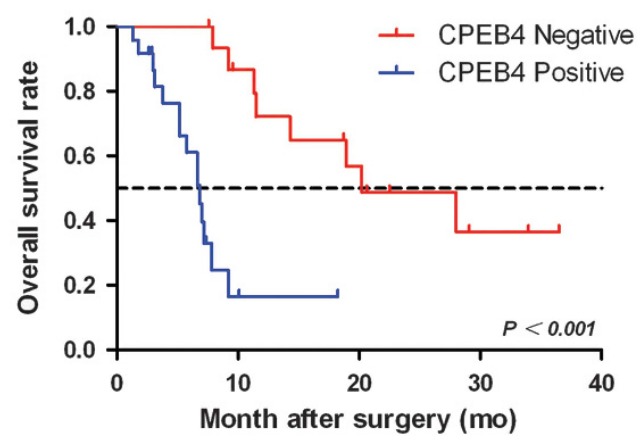

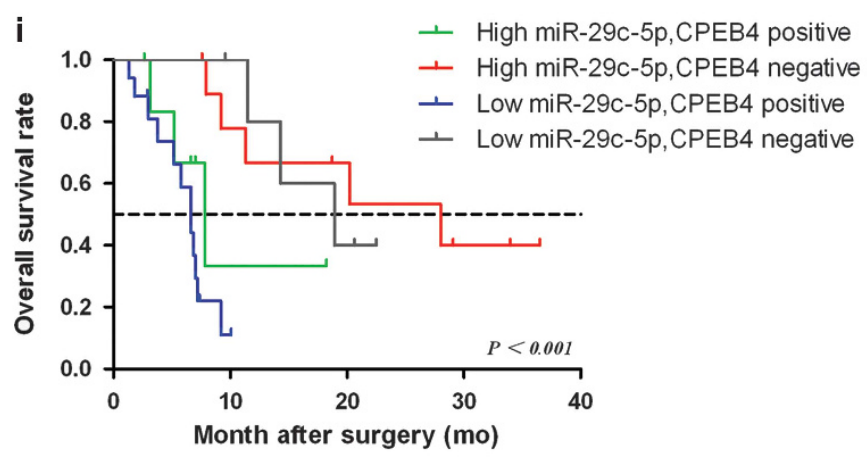

Figure 5 CPEB4 is a direct target of miR-29c-5p in GBC cells. (a) Potential miR-29c-5p targets predicted by two computational prediction programs. The overlap between themis listed (right). (b) Luciferase reporter plasmids were constructed as described in the materials and methods. The sequences of the predicted miR-29c-5p binding sites within the $3^{\prime}$ UTR of CPEB4 are shown, including the wild-type and mutant binding site. Relative luciferase activity was analyzed after co-transfection of the above reporter plasmids or a mock reporter plasmid into $293 \mathrm{~T}$ cells that were infected with pre-miR-29c $\left.{ }^{* \star *} P<0.001\right)$. (c) Western blot analysis of CPEB4 protein in GBC-SD and NOZ cells infected with anti-miR-29c-5p, anti-NC, pre-miR-NC, or pre-miR-29c. (d) CPEB4 mRNA levels in 40 pairs of GBC tissues and their corresponding NATs. (e and f) The correlation between the expression levels of miR-29c-5p and CPEB4 was determined using a linear regression analysis and a paired t-test with the same samples used in Figure $5 \mathrm{~d}$ $(\mathrm{P}<0.001, \mathrm{R}=-0.571$; Pearson's correlation). (g) Representative IHC micrographs showing CPEB4 protein expression in GBC tissues with high or low miR-29c-5p expression. Scale bar, $100 \mu \mathrm{m}$. (h) The OS of patients with positive or negative CPEB4 expression. (i) The OS rates of $40 \mathrm{GBC}$ patients were compared between the high and low miR-29c-5p expression groups and the high and low CPEB4 expression groups by using Kaplan-Meier analysis. $P$-values were generated from all groups together 
Negative correlation between miR-29c-5p and CPEB4 expression in GBC patients. To further evaluate the clinical relevance of the miR-29c-5p-mediated regulation of CPEB4 in clinical GBC specimens, we examined the levels of $C P E B 4$ mRNA in 40 pairs of GBC tissues and their corresponding NATs. Our qRT-PCR assays showed that CPEB4 expression was significantly upregulated in GBC tissues compared with the NATs (Figure 5d and Supplementary Figure S3B). Using Pearson correlation analysis, we calculated a significant inverse correlation between miR-29c-5p and CPEB4 mRNA levels in tumor specimens $(R=-0.571, P<0.001$; Figures $5 e$ and f). As illustrated in Supplementary Figure S3C, enrichment of CPEB4 protein was found primarily in tumor tissues, as opposed to in cholelithiasis tissues. This was closely related with the metastasis of lymph nodes. In accord with our findings, we also found that GBC patient tumors with high miR-29c-5p levels showed weak CPEB4 IHC staining, whereas tumors with low miR-29c-5p levels showed strong CPEB4 staining $(P<0.05$; Figure $5 \mathrm{~g})$. Moreover, elevated expression of CPEB4 among the 40 GBC specimens also predicted poor patient prognosis (Figure $5 \mathrm{~h}$ and Supplementary Figure S3E). Those patients with both a decreased level of miR-29c-5p and an elevated level of CPEB4 exhibited an even worse prognosis, suggesting that the combination of these two factors provides increased prognostic accuracy compared with each factor alone (Figure 5i and Supplementary Figure S3F). Furthermore, univariate and multivariate Cox regression analyses confirmed that CPEB4 expression level and lymph node metastasis are independent indicators of OS and DFS (Supplementary Figure S3D). Collectively, these results strongly indicated that the newly discovered miR-29c-5p/ CPEB4 axis has a pivotal role in the progression of GBC and might serve as a valuable biomarker for predicting the clinical recurrence and poor survival of GBC.

Gain and loss of CPEB4 function abrogates and mimics, respectively,the impact of miR-29c-5p on cell proliferation and metastasis. To determine whether the miR-29c-5pdependent inhibition of GBC cell proliferation and metastasis was indeed mediated by CPEB4, we first examined the function of CPEB4 in GBC cells. We found that knockdown of CPEB4 in GBC-SD cells, which harbor a high endogenous level of CPEB4 protein, significantly reduced cell proliferation, colony formation, cell migration as determined by a Transwell assay, and xenograft tumor growth (Supplementary Figures S4A-E), thus indicating a protumorigenic role for CPEB4 in GBC cells. In support of this notion, ectopic expression of CPEB4 in NOZ cells, which display a normal endogenous CPEB4 level, significantly promoted cell proliferation, colony formation, cell migration, and tumor growth in nude mice (Supplementary Figures S4F-J). Western blot analyses confirmed that the expression of phosphorylated MEK ( $p$ MEK), p-ERK, and p-AKT was reduced by knockdown of CPEB4 in GBC cells and enhanced by overexpression of CPEB4 in NOZ cells (Supplementary Figures S4C and H). Collectively, these results demonstrate that CPEB4 has a protumorigenic role in GBC cells.

We next used a complementary approach to examine gain and loss of CPEB4 function. Specifically, we knocked down the expression of CPEB4 in GBC-SD cells or restored CPEB4 expression in NOZ cells with a CPEB4 expression vector lacking the $3^{\prime}$ UTR. Restoration of CPEB4 expression enhanced the proliferation of and colony formation by miR-29c-5p-expressing NOZ cells (Figures $6 a$ and b). Similarly, flow cytometry analysis showed that restoration of CPEB4 expression recovered the cell cycle arrest caused by overexpression miR-29c-5p (Figure 6c). Moreover, restoration of CPEB4 significantly attenuated the miR-29c-5p-mediated inhibition of GBC cell migration and invasion (Figure 6d and Supplementary Figure S5B). In contrast, siCPEB4-mediated inhibition of CPEB4 expression mimicked the effect of miR-29c-5p on the proliferation and colony-formation capacity of GBC-SD cells (Figures $6 a$ and $b$ ). In addition, inhibition of CPEB4 expression also abrogated the anti-miR-29c-5pmediated inhibition of GBC-SD cell migration and invasion (Figure 6d and Supplementary Figure S5B). Candidate proteins in the MAPK/ERK signaling pathway were further analyzed by western blot. The results showed that the levels of p-MEK, p-ERK, and p-AKT were affected by ectopic expression or knockdown of miR-29c-5p and that these effects were abrogated by the reintroduction or inhibition of CPEB4, respectively (Figure 6e). These findings support the idea that CPEB4 represents an important target in the underlying mechanism of the tumor-suppressive functions of miR-29c-5p in $\mathrm{GBC}$.

Repression of miR-29c-5p is necessary for TGF- $\beta$ induced cell proliferation and metastasis. TGF- $\beta$ is one of the most potent cytokines linked to inflammation and metastasis in various types of cancers. ${ }^{23,24}$ However, there are few reports on functional experiments with regard to the correlation between miRNAs and expression of TGF- $\beta$ in GBC. ${ }^{10}$ We investigated whether TGF- $\beta$ is involved in the pathogenesis of GBC and in miR-29c-5p/CPEB4-induced tumor metastasis. To do so, we treated GBC cells with TGF- $\beta$ (Supplementary Figures S5A and D). Interestingly, we found that TGF- $\beta$ treatment significantly decreased the expression of miR-29c-5p and increased the level of CPEB4 mRNA, suggesting that TGF- $\beta$ negatively regulates the miR-29c-5p/ CPEB4 axis in GBC cells (Figures $7 a$ and b). Next, we examined whether a miR-29c-5p mimic could inhibit TGF- $\beta$-induced GBC metastasis and invasion. As expected, TGF- $\beta$-induced cell proliferation and migration were attenuated by incubation with pre-miR-29c (Figures 7c and $d$ and Supplementary Figure $\mathrm{S} 5 \mathrm{C}$ ). These results were further verified by a western blot assay for several EMT-related proteins (Figure 7e).

Together, these results indicate that the miR-29c-5p/CPEB4 axis has a pivotal role in TGF- $\beta$-induced metastasis (Figure 7f) and strongly support the conclusion that miR-29c-5p has an important role in mediating the link between inflammation and cancer.

\section{Discussion}

Previous evidence indicates a crucial role for miRNAs in human cancer. ${ }^{5,10}$ Expression profiling of miRNAs has been utilized for the classification of tumor stages and to establish prognoses. ${ }^{23,24}$ In the present study, we screened the miRNA 

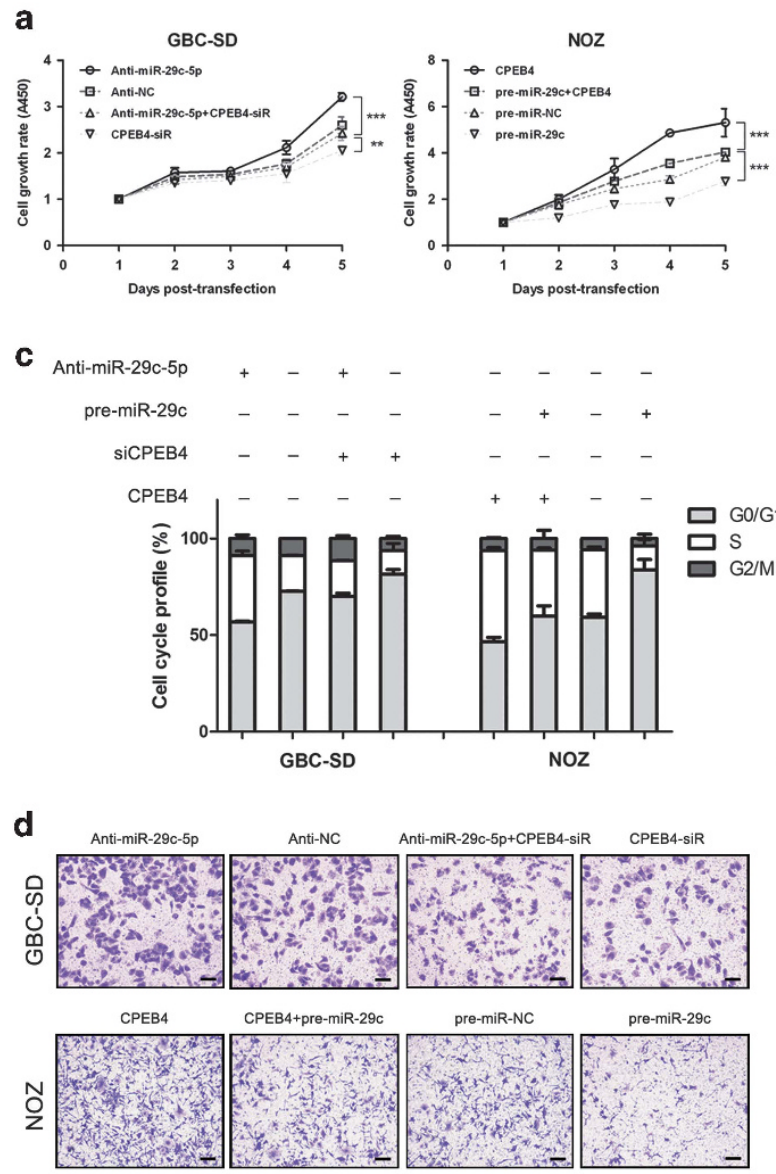

b

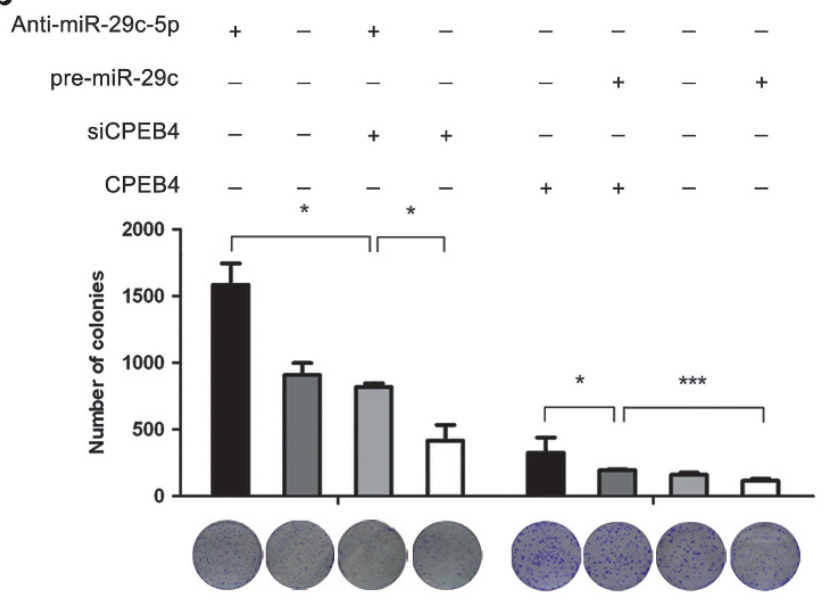

e

CPEB4

p-MEK1/2(Ser217)
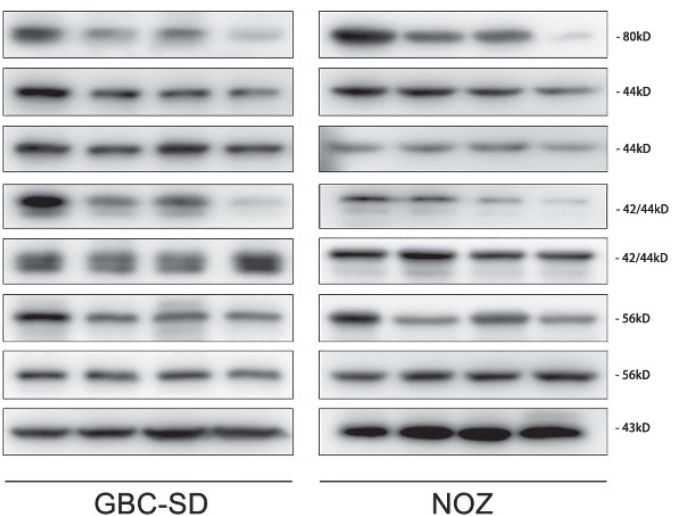

Figure 6 Gain- and loss-of-function studies with a CPEB4 expression vector or with siCPEB4. To investigate whether CPEB4 expression may interfere with or mimic the function of miR-29c-5p, GBC cells were transfected with CPEB4 siRNA or a CPEB4 expression vector to inhibit or to restore, respectively, the expression of CPEB4. Cell growth curves (a), colony-formation (b), FCM analysis (c), and migration assays (d) were performed with the above cells. (e) Western blot for CPEB4 and its downstream proteins in GBC cells that were stably infected with CPEB4, siCPEB4, or reintroduced control vector $\left({ }^{\star} P<0.05,{ }^{* *} P<0.01\right.$, and $\left.{ }^{* * *} P<0.001\right)$

expression patterns of GBC tumor and para-tumor tissues and found that miR-29c-5p was a GBC-associated miRNA. Further studies found that miR-29c-5p was frequently downregulated in GBC tissues compared with their nontumoral counterparts.

The miR-29 family members (miR-29a, miR-29b, and miR-29c), which differ in their last few 3 '-end nucleotides, act as tumor suppressors and are downregulated in human cancers, including colon cancer, ${ }^{25}$ non-small cell lung cancer, ${ }^{26}$ nasopharyngeal carcinoma, ${ }^{27}$ prostate cancer, ${ }^{28}$ and invasive breast cancer. ${ }^{29}$ The putative tumor suppressor miR-29c-3p impedes tumor development and progression by downregulating several oncogenes. ${ }^{11,26,30-33}$ Nevertheless, the precise role of miR-29c-5p in tumorigenesis remained largely unknown prior to this study.

A series of in vitro and in vivo assays showed that cancer cell growth, DNA replication, and colony formation were significantly decreased by overexpression of miR-29c-5p, suggesting that it has roles in GBC cell proliferation and tumor growth. The antiproliferative effect of miR-29c-5p overexpression appeared to be associated with a change in cell distribution amongst the cell cycle phases over time. This finding was confirmed by our observations of changes in the levels of cell cycle regulator proteins.Additionally, we found that miR-29c-5p has a pivotal role in GBC metastasis by EMT induction.

It is well known that the average miRNA has $\sim 100$ target sites and regulates a large fraction of protein-coding genes. ${ }^{34}$ To further explore the molecular mechanisms underlying the miR-29c-5p-induced apoptotic effect, we examined the altered mRNA expression profiles of GBC cells after transfection with miR-29c-5p. Our data show that miR-29c-5p contributes to apoptosis through inactivation of the MAPK/ERK pathway, which subsequently activates the caspase 9/caspase 3/PARP pathway. Therefore, the impaired GBC cell growth and metastasis mediated by miR-29c-5p overexpression can be explained, at least in part, by inactivation of the MAPK/ERK pathway. Previous reports show that the MAPK/ERK pathway is a classical signaling pathway whose activation induces cell growth, promotes $\mathrm{EMT}^{35}$ and stimulates Bax-mediated apoptosis. ${ }^{36-38}$ Thus, the results of our study may provide a basis for exploring potential novel therapeutic target in GBC. The tumor suppressor p53 is central to many cellular stress responses. In the nucleus p53 acts as a transcription factor, 


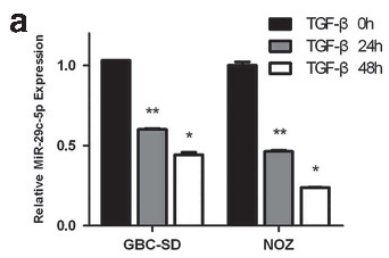

CPEB4

$\beta$-actin

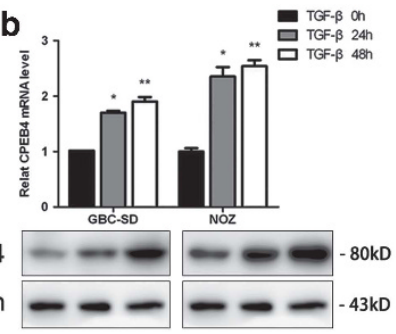

C
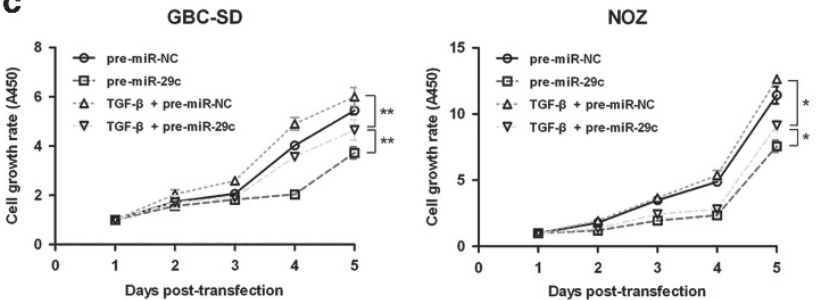

d
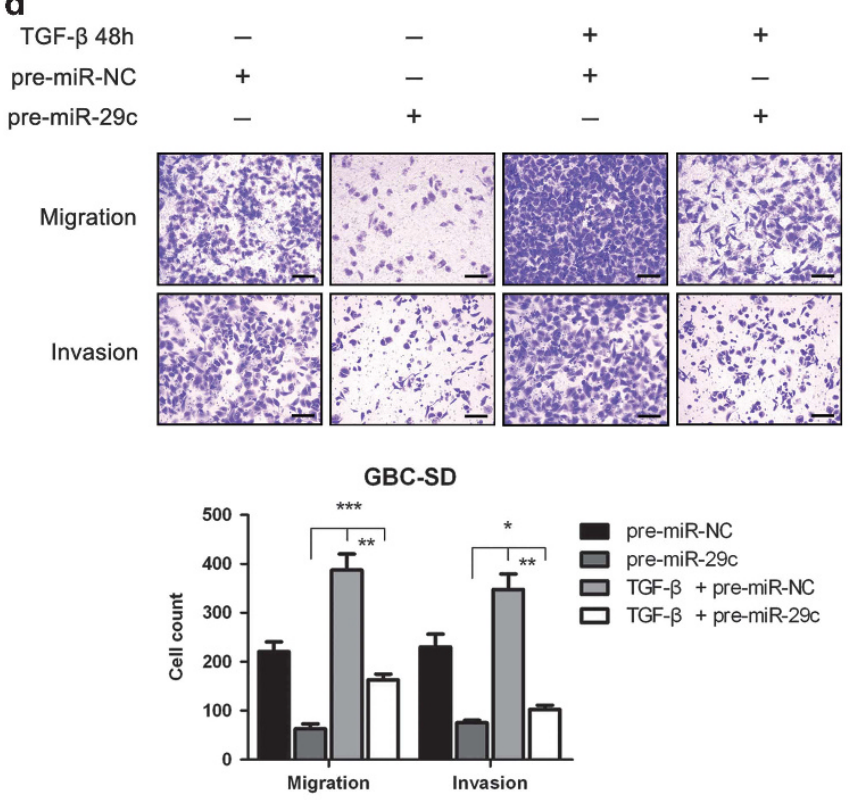

e

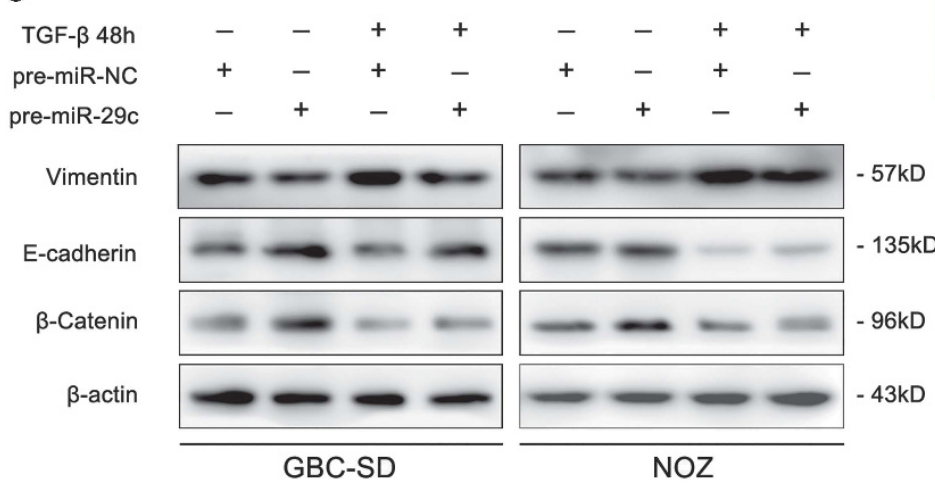

f

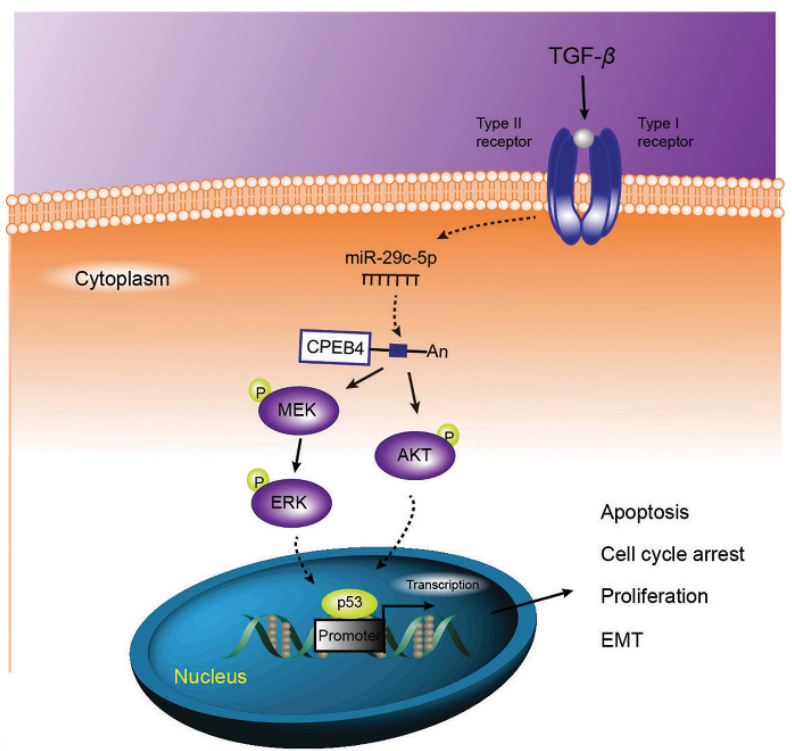

$\longrightarrow$ stimulate

........ inhibit

Figure 7 Reduced expression of miR-29c-5p is required for TGF- $\beta$-induced cell proliferation and metastasis. (a and $\mathbf{b}$ ) Relative changes in miR-29c-5p and CPEB4 expression in GBC-SD and NOZ cells after $48 \mathrm{~h}$ of stimulation with TGF- $\beta\left({ }^{\star} P<0.05,{ }^{* *} P<0.01\right.$, and $\left.{ }^{* * *} P<0.001\right)$. (c-e) GBC cells were treated with TGF- $\beta(10 \mathrm{ng} / \mathrm{ml})$ alone, TGF- $\beta$ plus pre-miR-NC, or TGF- $\beta$ plus pre-miR-29c for $48 \mathrm{~h}$ before cell growth curves, migration assays, and EMT-related gene expression were examined in the indicated cells $\left({ }^{*} P<0.05,{ }^{* *} P<0.01\right.$, and $\left.{ }^{* *} P<0.001\right)$. (f) Schematic depiction of the function and potential mechanism of miR-29c-5p in GBC

but when localized in mitochondria, p53 interacts with proapoptotic or antiapoptotic proteins and directly induces apoptosis. ${ }^{39}$ Recent studies showed that miRNAs participate in the downstream signaling of the p53 pathway. P53 binds directly to the promoter and trans-activates miR-34 genes in response to DNA damage and oncogenic stress. ${ }^{40,41}$ Our data show that miR-29c-5p indirectly upregulates TP53 promoter activity. These results suggested that miR-29c-induced apoptosis in GBC was dependent on p53.

Furthermore, the data presented here demonstrated that CPEB4, which is known to be protumorigenic in pancreatic ductal adenocarcinoma, ${ }^{42}$ is a novel target of miR-29c-5p and that miR-29c-5p exerts its tumor-suppressive function in GBC cells, at least in part, through repressing CPEB4. CPEB4 
associates with specific mRNA sequences in their $3^{\prime}$ UTRs and promotes translation by inducing cytoplasmic polyadenylation. ${ }^{22}$ Irrespective of the various mechanisms by which CPEB proteins may regulate translation, many CPEB family members mediate malignant transformation. ${ }^{43}$ It has been reported that CPEB4 is overexpressed in pancreatic ductal adenocarcinomas and has a crucial role in posttranscriptional gene regulation during pancreatic cancer progression. ${ }^{42}$ The precise mechanisms regulating CPEB4 expression, and the relationship between CPEB4 and miR$-29 c-5 p$, have not previously been reported in the context of GBC. In the present study, CPEB4 was identified as an oncogene that contributed to cancer progression. Nevertheless, the physiological significance of CPEB4 underlying the tumorigenicity and progression of $\mathrm{GBC}$ remains elusive. In our study, we demonstrated with a luciferase-based reporter assay that miR-29c-5p can bind to a sequence within the 3' UTR of CPEB4. The regulation of CPEB4 expression by miR-29c-5p was further validated by complementary gain- and loss-of-function approaches. Importantly, ectopic expression of CPEB4 could effectively abrogate miR-29c-5p-mediated inhibition of proliferation and metastasis. Our study provides solid evidence that miR-29c-5p inhibits the proliferation and metastasis of GBC cells by directly targeting CPEB4. Conversely, ectopic expression of CPEB4 could clearly promote proliferation, migration, and invasion in vitro and in vivo through the MAPK/ERK pathway. These results are the first to strongly indicate a key role for CPEB4 in the progression of GBC.

Although the role of inflammation in the initiation and progression of cancer has been well established, ${ }^{44}$ the underlying molecular mechanisms in GBC are incompletely understood. The cytokine TGF- $\beta$ is highly expressed in various types of cancer cells and acts as one of the most potent inducers of metastasis. In our functional studies, we found that CPEB4 is a novel target of miR-29c-5p and that TGF- $\beta$ represses miR-29c-5p, resulting in post-transcriptional upregulation of CPEB4 expression and subsequent inhibition of TGF- $\beta$ induced EMT and thereby forming a negative feedback loop that promotes tumor cell metastasis.

In conclusion, our results show that miR-29c-5p is significantly downregulated in GBC. TGF- $\beta$-induced reduction in the expression of miR-29c-5p has pivotal roles in GBC proliferation and metastasis in vitro and in vivo through the MAPK/ERK pathway and in the induction of EMT by directly targeting the transcription of CPEB4.These results provide new mechanistic insight into the molecular pathogenesis of TGF- $\beta$-mediated GBC metastasis and provide potential novel therapeutic targets for the treatment of GBC.

\footnotetext{
Materials and Methods

Patients, specimens, and cell lines. This study was approved by the ethics committee of Xinhua Hospital, and all patients provided informed consent. Fresh GBC tissue samples, tumor specimens, and nontumorous adjacent tissues (NATs) were obtained from $40 \mathrm{GBC}$ patients who underwent surgical operation without prior radiotherapy or chemotherapy between 2010 and 2013 at the Department of General Surgery, Xinhua Hospital, School of Medicine, Shanghai Jiao Tong University, China. In addition, 40 patients with cholelithiasis who underwent a simple cholecystectomy were included as controls. All the diagnoses of GBC, cholelithiasis, and lymph node metastasis were confirmed by a histopathological examination. The OS was defined as the interval between the
}

dates of surgery and death. An OS exceeding 36 months was considered the censored value. The tissue specimens had been fixed in $4 \%$ formalin immediately after their removal and were embedded in paraffin for immunohistochemical (IHC) staining. Fresh GBC tissue samples were used for qRT-PCR analysis. These samples were processed within 15 min of their surgical removal. Each sample was frozen and stored at $-80^{\circ} \mathrm{C}$. The NATs were dissected at least $2 \mathrm{~cm}$ away from the tumor border and were confirmed to lack tumor cells by microscopy. The clinical and pathological features of these patients are described in Supplementary Table 1.

The GBC cell lines GBC-SD, SGC-996, and the normal biliary epithelia cell line HIBEC were purchased from Shanghai Institute for Biological Science, Chinese Academy of Science (Shanghai, China). NOZ, OCUG, and EH-GB-1 were obtained from the Health Science Research Resources Bank (Osaka, Japan). The GBC-SD, NOZ, OCUG, EH-GB-1, HIBEC cells were cultured in high-glucose DMEM (Gibco, NY, USA) supplemented with $10 \%$ fetal bovine serum (FBS) (Gibco), $100 \mu \mathrm{g} / \mathrm{ml}$ streptomycin, and $100 \mathrm{U} / \mathrm{ml}$ penicillin (Gibco). The SGC-996 cells were cultured in Rosewell Park Memorial Institute (RPMI) 1640 medium, supplemented with 10\% FBS, $100 \mu \mathrm{g} / \mathrm{ml}$ streptomycin and $100 \mathrm{U} / \mathrm{ml}$ penicillin. Cells were incubated at $37^{\circ} \mathrm{C}$ in a humidified atmosphere of $95 \%$ air and $5 \% \mathrm{CO}_{2}$. Cell lines were tested 1 month before the experiment by methods of morphology check by microscopy, growth curve analysis, and mycoplasma detection according to the cell line verification test recommendations.

\section{Conflict of Interest}

The authors declare no conflict of interest.

Acknowledgements. This study was supported by the National Natural Science Foundation of China (No. 81172026, 81272402, 81301816, and 81172029), the National High Technology Research, and Development Program (863 Program) (No. 2012AA022606), the Program for Changjiang Scholars, the Natural Science Research Foundation of Shanghai Jiao Tong University School of Medicine (No. 13XJ10037), the Leading Talent program of Shanghai and Specialized Research Foundation for the PhD Program of Higher Education-Priority Development Field (No. 20130073130014 ), the Shanghai Sailing Program (16YF1407100), the Shanghai Municipal Commission of Health and Family Planning Youth Scientific Research Program (2016Y0087), the Doctoral Innovation Fund Projects from Shanghai Jiao Tong University School of Medicine (No. BXJ201426), and the Hangzhou Science and Technology Commission Project (No. 20140633B04).

\section{Author contributions}

SYJ, WZ, and JL were responsible for the experimental design. SYJ contributed to the execution of experiments, data statistics, and manuscript composition. BRF, WXA, and $\mathrm{ZF}$ participated in performing the experiment and in the manuscript mapping and submission. LHB, YYY, XSS, and LHF participated in the discussion and data interpretation. WH, LML, WXS, HYP,LW, and ZYJ conceived the study and revised the manuscript. ZJ, DP, and LYB was responsible for the funding application, and the supervision and management of the project. All authors have contributed to and approved the final manuscript.

1. Wu XS, Shi LB, Li ML, Ding Q, Weng H, Wu WG et al. Evaluation of two inflammation-based prognostic scores in patients with resectable gallbladder carcinoma. Ann Surg Oncol 2014; 21: $449-457$

2. Liu TY, Gong W, Tan ZJ, Lu W, Wu XS, Weng H et al. Baicalein inhibits progression of gallbladder cancer cells by downregulating ZFX. PloS One 2015; 10: e0114851.

3. Li M, Zhang Z, Li X, Ye J, Wu X, Tan Z et al. Whole-exome and targeted gene sequencing of gallbladder carcinoma identifies recurrent mutations in the ErbB pathway. Nat Genet 2014; 46: $872-876$

4. Shu YJ, Weng H, Bao RF, Wu XS, Ding Q, Cao Y et al. Clinical and prognostic significance of preoperative plasma hyperfibrinogenemia in gallbladder cancer patients following surgical resection: a retrospective and in vitro study. BMC Cancer 2014; 14: 566.

5. Bertoli G, Cava C, Castiglioni I. MicroRNAs: new biomarkers for diagnosis, prognosis, therapy prediction and therapeutic tools for breast cancer. Theranostics 2015; 5: 1122-1143.

6. Lee RC, Feinbaum RL, Ambros V. The C. elegans heterochronic gene lin- 4 encodes small RNAs with antisense complementarity to lin-14. Cell 1993; 75: 843-854.

7. Wightman B, Ha I, Ruvkun G. Posttranscriptional regulation of the heterochronic gene lin-14 by lin-4 mediates temporal pattern formation in C. elegans. Cell 1993; 75: 855-862.

8. Fang F, Chang RM, Yu L, Lei X, Xiao S, Yang H et al. MicroRNA-188-5p suppresses tumor cell proliferation and metastasis by directly targeting FGF5 in hepatocellular carcinoma. J Hepatol 2015; 63: 874-885. 
9. Xu L, Beckebaum S, lacob S, Wu G, Kaiser GM, Radtke A et al. MicroRNA-101 inhibits human hepatocellular carcinoma progression through EZH2 downregulation and increased cytostatic drug sensitivity. J Hepatol 2014; 60: 590-598.

10. Chang Y, Liu C, Yang J, Liu G, Feng F, Tang J et al. MiR-20a triggers metastasis of gallbladder carcinoma. J Hepatol 2013; 59: 518-527.

11. Jiang J, Yu C, Chen M, Zhang H, Tian S, Sun C. Reduction of miR-29c enhances pancreatic cancer cell migration and stem cell-like phenotype. Oncotarget 2015; 6: 2767-2778.

12. Wang CM, Wang Y, Fan CG, Xu FF, Sun WS, Liu YG et al. miR-29c targets TNFAIP3, inhibits cell proliferation and induces apoptosis in hepatitis $B$ virus-related hepatocellular carcinoma. Biochem Biophys Res Commun 2011; 411: 586-592.

13. Parpart S, Roessler S, Dong F, Rao V, Takai A, Ji J et al. Modulation of miR-29 expression by alpha-fetoprotein is linked to the hepatocellular carcinoma epigenome. Hepatology 2014; 60 : 872-883

14. Landvik NE, Arlt VM, Nagy E, Solhaug A, Tekpli X, Schmeiser HH et al. 3-Nitrobenzanthrone and 3-aminobenzanthrone induce DNA damage and cell signalling in Hepa1c1c7 cells Mutat Res 2010; 684: 11-23.

15. Inoue $Y$, Kitagawa M, Taya $Y$. Phosphorylation of $p R B$ at Ser612 by Chk1/2 leads to a complex between pRB and E2F-1 after DNA damage. EMBO J 2007; 26: 2083-2093.

16. Wang $\mathrm{H}$, Shi J, Luo Y, Liao Q, Niu Y, Zhang F et al. LIM and SH3 protein 1 induces TGFbetamediated epithelial-mesenchymal transition in human colorectal cancer by regulating S100A4 expression. Clin Cancer Res 2014; 20: 5835-5847.

17. Liu Y, Shi QF, Qi M, Tashiro S, Onodera S, Ikejima T. Interruption of hepatocyte growth facto signaling augmented oridonin-induced death in human non-small cell lung cancer A549 cells via c-met-nuclear factor-kappaB-cyclooxygenase-2 and c-Met-Bcl-2-caspase-3 pathways. Biol Pharm Bull 2012; 35: 1150-1158.

18. Pal S, Pal PB, Das J, Sil PC. Involvement of both intrinsic and extrinsic pathways in hepatoprotection of arjunolic acid against cadmium induced acute damage in vitro. Toxicology 2011; 283: 129-139.

19. Ewings KE, Wiggins CM, Cook SJ. Bim and the pro-survival Bcl-2 proteins: opposites attract ERK repels. Cell Cycle 2007; 6: 2236-2240.

20. Das A, Banik NL, Patel SJ, Ray SK. Dexamethasone protected human glioblastoma U87MG cells from temozolomide induced apoptosis by maintaining Bax:Bcl-2 ratio and preventing proteolytic activities. Mol Cancer 2004; 3: 36.

21. Park SY, Lee JH, Ha M, Nam JW, Kim VN. miR-29 miRNAs activate p53 by targeting p85 alpha and CDC42. Nat Struct Mol Biol 2009; 16: 23-29.

22. Xu H, Liu B. CPEB4 is a candidate biomarker for defining metastatic cancers and directing personalized therapies. Med Hypotheses 2013; 81: 875-877.

23. Yang X, Zhang XF, Lu X, Jia HL, Liang L, Dong QZ et al. MicroRNA-26a suppresses angiogenesis in human hepatocellular carcinoma by targeting hepatocyte growth factor-cMet pathway. Hepatology 2014; 59: 1874-1885.

24. Altman DG, McShane LM, Sauerbrei W, Taube SE. Reporting recommendations for tumor marker prognostic studies (REMARK): explanation and elaboration. PLOS Med 2012; 9: e1001216.

25. Cummins JM, He Y, Leary RJ, Pagliarini R, Diaz LA Jr., Sjoblom T et al. The colorectal microRNAome. Proc Natl Acad Sci USA 2006; 103: 3687-3692.

26. Fabbri M, Garzon R, Cimmino A, Liu Z, Zanesi N, Callegari E et al. MicroRNA-29 family reverts aberrant methylation in lung cancer by targeting DNA methyltransferases $3 \mathrm{~A}$ and $3 \mathrm{~B}$. Proc Natl Acad Sci USA 2007; 104: 15805-15810

27. Sengupta S, den Boon JA, Chen IH, Newton MA, Stanhope SA, Cheng YJ et al. MicroRNA $29 \mathrm{c}$ is down-regulated in nasopharyngeal carcinomas, up-regulating mRNAs encoding extracellular matrix proteins. Proc Natl Acad Sci USA 2008; 105: 5874-5878.

28. Porkka KP, Pfeiffer MJ, Waltering KK, Vessella RL, Tammela TL, Visakorpi T. MicroRNA expression profiling in prostate cancer. Cancer Res 2007; 67: 6130-6135.

29. Iorio MV, Ferracin M, Liu CG, Veronese A, Spizzo R, Sabbioni S et al. MicroRNA gene expression deregulation in human breast cancer. Cancer Res 2005; 65: 7065-7070.
30. Wang Y, Zhang X, Li H, Yu J, Ren X. The role of miRNA-29 family in cancer. Eur J Cell Biol 2013; 92: 123-128.

31. Zhao X, Li J, Huang S, Wan X, Luo H, Wu D. MiRNA-29c regulates cell growth and invasion by targeting CDK6 in bladder cancer. Am J Trans/ Res 2015; 7: 1382-1389.

32. Cristobal I, Madoz-Gurpide J, Manso R, Rojo F, Garcia-Foncillas J. MiR-29c downregulation contributes to metastatic progression in colorectal cancer. Ann Oncol 2015; 26: 2199-2200.

33. Pekarsky Y, Santanam U, Cimmino A, Palamarchuk A, Efanov A, Maximov V et al. Tcl1 expression in chronic lymphocytic leukemia is regulated by miR-29 and miR-181. Cancer Res 2006; 66: 11590-11593.

34. Brennecke J, Stark A, Russell RB, Cohen SM. Principles of microRNA-target recognition PLoS Biol 2005; 3: e85.

35. Wang ZC, Gao Q, Shi JY, Guo WJ, Yang LX, Liu XY et al. Protein tyrosine phosphatase receptor $S$ acts as a metastatic suppressor in hepatocellular carcinoma by control of epithermal growth factor receptor-induced epithelial-mesenchymal transition. Hepatology 2015; 62: 1201-1214.

36. Loi S, Dushyanthen S, Beavis PA, Salgado R, Denkert C, Savas P et al. RAS/MAPK activation is associated with reduced tumor-infiltrating lymphocytes in triple-negative breast cancer: therapeutic cooperation between MEK and PD-1/PD-L1 immune checkpoint inhibitors. Clin Cancer Res 2015; 22: 1499-1509.

37. Fabris L, Berton S, Pellizzari I, Segatto I, D'Andrea S, Armenia J et al. p27kip1 controls $\mathrm{H}$-Ras/MAPK activation and cell cycle entry via modulation of MT stability. Proc Natl Acad Sci USA 2015; 112: 13916-13921.

38. Wang $\mathrm{H}$, An $\mathrm{H}$, Wang $\mathrm{B}$, Liao $\mathrm{Q}$, Li W, Jin $\mathrm{X}$ et al. miR-133a represses tumour growth and metastasis in colorectal cancer by targeting LIM and SH3 protein 1 and inhibiting the MAPK pathway. Eur J Cancer 2013; 49: 3924-3935.

39. Vousden KH, Prives C. P53 and prognosis: new insights and further complexity. Cell 2005 120: $7-10$.

40. Raver-Shapira N, Marciano E, Meiri E, Spector Y, Rosenfeld N, Moskovits N et al. Transcriptional activation of miR-34a contributes to p53-mediated apoptosis. Mol Cell 2007; 26: 731-743.

41. Bommer GT, Gerin I, Feng Y, Kaczorowski AJ, Kuick R, Love RE et al. p53-mediated activation of miRNA34 candidate tumor-suppressor genes. Curr Biol 2007; 17: 1298-1307.

42. Ortiz-Zapater E, Pineda D, Martinez-Bosch N, Fernandez-Miranda G, Iglesias M, Alameda F et al. Key contribution of CPEB4-mediated translational control to cancer progression. Nat Med 2012; 18: 83-90.

43. D'Ambrogio A, Nagaoka K, Richter JD. Translational control of cell growth and malignancy by the CPEBs. Nat Rev Cancer 2013; 13: 283-290.

44. Wang L, Zhang LF, Wu J, Xu SJ, Xu YY, Li D et al. IL-1beta-mediated repression of microRNA-101 is crucial for inflammation-promoted lung tumorigenesis. Cancer Res 2014 74: $4720-4730$.

(c) (i) (2) This work is licensed under a Creative Commons Attribution-NonCommercial-ShareAlike 4.0 International License. The images or other third party material in this article are included in the article's Creative Commons license, unless indicated otherwise in the credit line; if the material is not included under the Creative Commons license, users will need to obtain permission from the license holder to reproduce the material. To view a copy of this license, visit http://creativecommons.org/licenses/by-nc-sa/4.0/

C) The Author(s) 2017

Supplementary Information accompanies this paper on Cell Death and Differentiation website (http://www.nature.com/cdd) 